\title{
The Effect of Control Priming on Irresponsible Financial Behavior
}

\author{
MOHAMMED EL HAZZOURI
}

$\&$

KELLEY J. MAIN

*Mohammed El Hazzouri is an associate professor in marketing in the Bissett School of Business, Mount Royal University, Calgary, AB (melhazzouri@mtroyal.ca). Kelley J. Main is a professor of marketing in the Asper School of Business, University of Manitoba, Winnipeg, MB (kelley_main@umanitoba.ca). This project was supported by funding from the Social Sciences and Humanities Council of Canada and the University Research Grants Program at University of Manitoba.

Correspondence: Mohammed El Hazzouri, Bissett School of Business, Mount Royal University, 4825 Mount Royal Gate, Calgary, Alberta, T3E 6K6, Tel: (403) 440 8439. Email: melhazzouri@mtroyal.ca

This is a post-peer-review, pre-copyedit version of an article published in Marketing Letters. The final authenticated version is available online at: http://dx.doi.org/10.1007/s11002-018-9457-6. 


\begin{abstract}
Debt has reached staggering levels among North Americans. Unfortunately, there is deficiency of research that investigates effective means of helping consumers control their debt. We examine how control priming changes consumers' irresponsible financial behavior. We show that control priming reduces credit card spending and intentions to take credit card risk. We also show that consumers who score high on self-esteem are more likely to benefit from control priming while those who score low on self-esteem show a backlash effect.
\end{abstract}

Keywords: Control Priming, Self-Efficacy, Self-Esteem, Credit Card Debt, Financial Risk, Attributional Retraining 


\section{The Effect of Control Priming on Irresponsible Financial Behavior}

It is estimated that consumer debt in the U.S. has reached approximately $\$ 12.73$ trillion, with credit card debt accounting for $\$ 764$ billion of this figure (Federal Reserve Bank of New York 2017). Even undergraduate students, a group that has had far less time to amass a credit history, are showing troubling signs as student loan debt has grown to $\$ 1.34$ trillion (Federal Reserve Bank of New York 2017). As a result of these trends, scholars have become increasingly interested in conducting research aimed at further understanding consumers' financial behavior. Most of these investigations have primarily employed survey research and have focused on factors that are associated with an individual's propensity to take financial risk and acquire debt (Lea, Webley, and Levine 1993). For example, Xiao, Tang, Serido, and Shim (2011) found that risky credit behavior is influenced by factors such as parental norms, socioeconomic status, and subjective financial knowledge. Furthermore, lack of self-control has also been shown to be associated with high debt (Gathergood 2012). Other researchers have examined consumers' misplaced belief in money as a source of power or prestige (Yamanchi and Templer 1982), as well as the mechanisms behind the emotional "high" that is often associated with credit card use (Hayhoe, Leach, and Turner 1999). More recently, experimental research has focused on understanding the factors that contribute to consumers' tendency to incur debt (Wilcox, Block, and Eisenstein 2011) and pay it off (Kettle, Trudel, Blanchard and Haubl 2016), and the consequences of using credit cards (Kamlietner and Erki 2013).

Our research adds to the body of literature that attempts to identify strategies that can motivate consumers to reduce their irresponsible financial behavior and control their debt accumulation. Across three studies, we investigate how priming consumers with thoughts of 
control affects their credit card spending, gambling behavior, and willingness to take credit card risk, all of which we refer to as irresponsible financial behavior.

Our findings indicate that control priming - in this case, suggestions that one's actions are internally controllable — can play a significant role in changing financial behavioral intentions and actual behaviors. Importantly, we find that the effect of control priming is mediated by financial self-efficacy. We also identify a boundary condition that demonstrates that control priming is most effective for individuals with high self-esteem, and that it backfires among those with low self-esteem.

This research makes several contributions. By investigating control priming in a consumer context, we reveal a previously undocumented mediator: self-efficacy. To our knowledge, no research has investigated self-efficacy as an underlying process for control priming. We further contribute to the literature by identifying self-esteem as a distinct boundary condition. Our research indicates that control priming is generally effective for individuals with high self-esteem, but has a negative effect on individuals with low self-esteem.

Practically speaking, we demonstrate the effectiveness of control priming as a tool for altering consumers' intentions and actual behavior vis-a-vis irresponsible financial behavior. Furthermore, our findings reveal that these control priming strategies may potentially have longlasting positive outcomes, as one study's results indicated a carry-over effect that was still observable one month later.

\section{Theoretical Development}

\section{Financial Self-Control}

Self-control is a person's ability to change their unwelcome desires and to avoid acting on them. As such, people with high self-control are better at avoiding impulsive consumption 
behaviors (Baumeister 2002; Tangney, Baumeister, and Boone 2004) and generally exhibit lower levels of irresponsible financial behavior (Xiao, Tang, Serido, and Shim 2011). In fact, as it relates to spending, self-control is negatively associated with discretionary spending, unplanned credit spending, debt accumulation, and financial stress (Bearden and Haws 2012; Haws, Bearden, and Nenkov 2012). Further, those who believe that the economic system gives them little financial control through limited economic mobility are more likely to engage in irresponsible financial behavior (Yoon and Kim 2016)

Although it is primarily an individual trait variable (Tangney et al. 2004), evidence suggests that individuals can be trained to improve their self-control (Muraven 2010). Thus, it is possible for individuals with poor self-control to improve their financial outcomes (Oaten and Cheng 2007). Similarly, strategies such as focusing on one's financial decisions can improve outcomes for people with low self-control (Haws et al. 2012). In our research, we suggest that control priming can produce comparable effects; that is, we suggest that control-primed individuals will be more likely to avoid financially irresponsible behaviors.

\section{Adaptive and Maladaptive Attributions}

According to attribution theory, individuals are motivated to seek out explanations for outcomes that are new, unexpected, or important (Weiner 1986). In response, people generate causal explanations that directly impact their subsequent cognitions, emotions, and behaviours. Weiner (1986) posits that there are three dimensions of causal attribution: locus of control, stability, and controllability. One stream of research has focused on how maladaptive stable, uncontrollable attributions can be retrained and changed into adaptive unstable, controllable attributions that lead to better adjustments to the external environment (Luzzo, James, and Luna 1996). This approach, known as "attributional retraining," investigates how to change the 
perception that outcomes are stable and uncontrollable (e.g. low ability), which is important because such perceptions can seriously threaten achievement and motivation (Perry and Penner 1990). Traditionally, attributional retraining focuses on impacting two of the main causal dimensions that influence attribution: stability and controllability. Attributional retraining proponents argue that, by increasing the extent to which an individual believes they have volitional control over an unstable cause, it is possible to increase the extent to which they actually attain success vis-a-vis outcomes linked to that cause.

While consumer researchers have yet to explore potential applications of attributional retraining, researchers in other fields have shown that it can be used successfully to deal with a range of personal challenges, including depression (Weiner and Litman-Adizes 1980), academic performance (Perry and Penner 1990), and university retention rates (Ruthig, Perry, Hall, and Hladkyj 2004). Typically, attributional retraining presents participants with information that focuses on the positive effects of control-related attributions. This information can be presented in a variety of forms, including videos, brief group discussions, or handouts (Ruthig et al 2004). For instance, a one-page handout will usually begin with a discussion about failure experiences before transitioning to a discussion about how an affected person can take more control of their situation. Thus, the handout focuses on helping affected individuals deal with failure more productively by giving them strategies for changing their dysfunctional causal attributions to ones that are more functional. Our intervention targets control-related attributions and is modeled on the handout/video methods used in other retraining research. We predict that we can positively influence consumers' beliefs about irresponsible financial behavior by encouraging them to focus on controlling their maladaptive attributions. This prediction is based on previous research, which has shown that individuals who lack a sense of self-control are more likely to 
engage in irresponsible financial behavior (Perry and Morris 2005; Plunkett and Buehner 2007). Given its effectiveness in academic achievement and other personal domains, we expect that priming consumers with control-related thoughts will decrease their willingness to engage in irresponsible financial behavior.

\section{Self-Esteem}

Despite the body of academic research on changing attributions, there has been little research exploring its moderators and the conditions under which it may be less effective. One exception to this trend has been research investigating loci of control and perceived controllability. Significantly, research on these variables has revealed that individuals with an external locus of control (i.e. those who tend to blame failure on external factors, including luck) or low perceived controllability (i.e. a low perceived contingency between action and outcome) benefit most from attributional retraining (e.g. Hall, Perry, Chipperfield, Clifton, and Haynes 2006; Perry and Penner 1990).

We suggest that control priming will be most effective for consumers with high selfesteem. Self-esteem refers to a person's favorable or unfavorable global self-evaluations (Baumeister, Campbell, Krueger, and Vohs 2003). Unlike individuals with low self-esteem, individuals with high self-esteem see themselves as competent, are more accepting of optimistic messaging, expect future success, are more persistent after failure, and are more likely to take initiative (Baumeister et al. 2003; Fitch 1970; Leventhal and Perloe 1962; McFarlin and Blascovich 1981). We expect that control priming will be most effective for consumers with high self-esteem because these individuals also tend to possess a greater sense of self-efficacy. As a result, these individuals will be more likely to possess the will and the ability to take control of their actions and to minimize their engagement in irresponsible financial behavior. Conversely, 
suggestions of self-control are expected to be less effective in reducing the willingness to take part in irresponsible financial behavior among consumers with low self-esteem. As suggested above, financial self-efficacy is expected to play a mediating role in the relationship between control priming and the modification of financial behavior.

\section{Financial Self-Efficacy}

Self-efficacy is a person's evaluation of their ability to undertake courses of action in order to attain a certain performance target (Bandura 1986). Self-efficacy reflects an individual's evaluation of whether their abilities and strategies are sufficient for achieving a particular end (Gist and Mitchel 1992). As such, self-efficacy influences whether the individual will adopt a given behavior, the degree of effort they will exert in doing so, and the length of time they will persist in maintaining that behavior in the face of barriers (Bandura 1977). In addition, selfefficacy has been found to correlate with a locus of control (Taylor and Popma 1990). Research has also found that attributional retraining interventions can enhance the career decision making efficacy of students (Luzzo, Funk, and Strang 1996). However, researchers have yet to test whether self-efficacy plays a mediating role. Within the context of the present research, we expect that control priming will enhance financial self-efficacy, which will in turn reduce consumers' willingness to engage in irresponsible financial behavior.

\section{Overview of Studies}

We conducted three experimental studies to evaluate how control priming affects irresponsible financial behavior. In Studies 1A and 1B, we examined control priming's influence on reported credit card spending and gambling behavior, respectively. In Study 2, we explored how control priming affected people's intentions to take credit card risk and the roles that selfefficacy and self-esteem play in this relationship. 


\section{Study 1A: The Effect of Control Priming on Credit Card Spending}

In this study, we examined whether control priming affects the irresponsible financial behavior of credit card debt accumulation. Accumulating credit card debt can be classified as a form of financially irresponsible behavior because the accompanying interest rates are typically higher than those of other forms of credit, including lines of credit (Financial Consumer Agency of Canada 2012). Therefore, credit card debt has a greater negative financial impact on the consumer than other forms of debt. We also investigated how long the effects of control priming lasted by examining consumer responses one month after being exposed to the manipulation.

\section{Method}

This study consisted of two phases. In Phase I, the participants were shown a video containing the control-priming manipulation. The video told the story of a student who had successfully managed to pay off their credit card debt (see Appendix A for script). By the end of the video, participants had either received a message that emphasized the possibility of controlling personal debt (control present), or they had received a message that contained no explicit mention of debt control (control absent). The video contained animated sketches of female or male characters and was narrated by either a female or a male. The genders of the characters and the narrator were matched to the gender of the participant. Phase II took place one month later where participants were sent a questionnaire asking about their spending behavior in preceding month.

One hundred and fifty one participants from a medium sized North American university who own credit cards completed the two phases of the study for course credit. Three participants were excluded from the analysis for reporting extreme spending $(Z>3)$. Thus the final sample consisted of one hundred and forty eight participants. 


\section{Measures}

Manipulation check. Participants in Phase I were asked to indicate the extent to which the video they watched emphasized taking control (1=not at all, 7 =very much).

Dependent Variable. Participants in Phase II were asked to report how much they had spent on their credit card in the month following the completion of Phase I. Other measures were included for exploratory purposes that are not reported here or in the other studies.

\section{Results}

Manipulation check. Participants in the control-present condition were more likely than those in the control-absent condition to indicate that the video emphasized taking control $\left(\mathrm{M}_{\text {present }}=6.51\right.$ vs. $\left.\mathrm{M}_{\text {absent }}=5.56, t(145)=-5.42, p<.0001\right)$ at the conclusion of Phase $\mathrm{I}$.

Dependent Variable. The results showed that control priming significantly predicted the reported amount of money spent on credit cards in Phase II (one month later). Participants in the control-present condition reported that they had spent an average of $\$ 130$ less on their credit card than the participants in the control-absent condition $\left(\mathrm{M}_{\text {present }}=\$ 330.01, \mathrm{SD}=347 \mathrm{vs}\right.$.

$\left.\mathrm{M}_{\mathrm{absent}}=\$ 462.90, \mathrm{SD}=469 ; \mathrm{t}(146)=1.96, \mathrm{p}=.05\right)$. In addition, log transformation was used to address data skewness. Results still showed that participants in the control-present condition reported spending less on their credit card than participants in the control-absent condition $\left(\mathrm{M}_{\text {present }}=2.09, \mathrm{SD}=.86\right.$ vs. $\left.\mathrm{M}_{\mathrm{absent}}=2.42, \mathrm{SD}=.55 ; \mathrm{t}(146)=2.79, \mathrm{p}<.01\right)$.

\section{Discussion}

The results of Study $1 \mathrm{~A}$ revealed that control priming can be an effective method of influencing irresponsible financial behavior. One alternative explanation for the obtained results may be that the participants in the control-present condition were more likely to present themselves in a socially desirable light by reporting that they spent less than those in the control- 
absent condition. We address this concern in Study 1B by measuring a different form of irresponsible financial behavior: gambling.

\section{Study 1B: The Effect of Control Priming on Gambling}

In this study, we tested whether control priming via a news article would affect participants' irresponsible financial behavior, this time in the form of gambling. We expected that participants in the control-present condition would be more likely to avoid gambling than the participants in the control-absent condition.

\section{Method and Participants}

The participants for this study were recruited via Amazon's Mechanical Turk and consisted of U.S. residents who own credit cards ( $\mathrm{N}=142 ; 40.8 \%$ female, $\left.\mathrm{M}_{\mathrm{age}}=36.38\right)$. Each participant read one of the two versions of the video script used in Study 1A (i.e. control present or control absent); however, for this study, the script was presented as an article written by a person reflecting on their personal credit card debt.

\section{Measures}

Manipulation check. Participants were asked to indicate the extent to which the article they read emphasized taking control ( $1=$ not at all, $7=$ very much). This was the same item used in Study 1A.

Gambling Behavior. Participants were required to make 7 hypothetical decisions: take a smaller guaranteed cash prize, or flip a coin (50\% chance of winning) for a larger one. The value of the larger, coin-toss cash prize varied across scenarios. If the participant elected to take the guaranteed prize, it was scored as 0 ; if they elected to gamble and go for the larger prize, it was scored as 1 . Thus, a participant who decided to gamble in all scenarios would obtain the 
maximum gambling score of 7. This measure was adopted from Hsee and Weber (1999) and was previously used by Levav and Argo (2010) to measure financial risk taking (See Appendix B).

\section{Results and Discussion}

Manipulation check. Participants in the control-present condition were more likely than those in the control-absent condition to indicate that the article emphasized taking control $\left(\mathrm{M}_{\text {present }}=6.65, \mathrm{M}_{\text {absent }}=5.93, t(140)=-4.07, p<.001\right)$.

Gambling Behavior. The results showed that control priming significantly reduced participants' inclination to gamble $\left(\mathrm{M}_{\text {present }}=0.52, \mathrm{M}_{\text {absent }}=0.94, t(139)=2.07, p<.05\right)$, which indicates that control priming can be an effective method for reducing irresponsible financial behavior. It is important to note that the gambling scenarios in this study were hypothetical and participants' decisions were therefore inconsequential. Nonetheless, taken together, the results of Studies 1A and 1B confirm that control priming is an effective method of reducing irresponsible financial behavior.

\section{Study 2: The Role of Self-Efficacy and Self-Esteem}

The goal of this study was to discover the process by which control priming affects irresponsible financial behavior. Specifically, this study was designed to determine whether financial self-efficacy mediates the relationship between control priming and irresponsible financial behavior, and whether self-esteem moderates the effect. However, unlike Studies 1A and $1 \mathrm{~B}$, this study employed a more general form of control priming in order to enhance the generalizability of the findings.

\section{Method and Participants}


Participants for this study were recruited via the Crowdflower research panel and consisted of two hundred and twenty U.S. residents who own credit cards (51.8\% female,

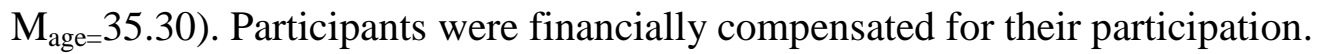

This study utilized a 2 (Control: absent vs. present) x Self-Esteem design. Control was manipulated by having participants read either a paragraph written by an individual who decided to take control of their life (control present), or a paragraph written by an individual who loves reading (control absent - See Appendix C). Self-esteem was measured as outlined below. It was expected that the control-primed participants would be less willing to engage in irresponsible financial behavior than the non-control-primed participants. It was also expected that participants with high self-esteem would be more likely to benefit from control priming. Self-efficacy was expected to be the process by which retraining affected irresponsible financial behavior. Figure 1 illustrates the proposed moderated mediation model.

\section{Insert Figure 1 about here}

\section{Measures}

Manipulation checks. Participants were asked if the paragraph they read emphasized taking control (1=not at all, $7=$ very much). This is the same measure used in Studies $1 \mathrm{~A}$ and 1B. Participants also reported the amount of credit card debt they were carrying at the time of the study and their monthly personal income. These items were used as covariates.

Self-esteem. Participants indicated their level of agreement (1=strongly disagree, 7 =strongly agree) on five items adopted from Rosenberg (1965). For example, one item stated: "I take a positive attitude toward myself." The five items were loaded on a single distinct factor and averaged to create an overall self-esteem scale $(\alpha=.92)$. 


\section{Dependent variables.}

Credit Card Risk. Participants used a seven-point scale (1=strongly disagree, $7=$ strongly agree) to respond to six items that were designed to assess their willingness to take on credit card risk within the next six months. The items were as follows: 1) I am likely to take cash advances on my credit card; 2) I am likely to have my credit limit increased if opportunity arises; 3) I will use my credit card to pay for things other than necessities; 4) I am likely to max out the limit of one or more of my credit cards; 5) I am likely to apply for a new credit card; and 6) I am likely to use high-interest store credit card(s). These items were loaded together on a single distinct factor and then averaged to create an overall willingness to take credit card risk index $(\alpha=.79)$.

Financial self-efficacy. Participants indicated their level of agreement (1=strongly disagree, $7=$ strongly agree) on four items designed to assess how they feel about financial management. The items, which were adopted from Lown (2011), included statements such as: "When unexpected expenses occur, I will have to use credit (R)". The four items were loaded on a single distinct factor and then averaged to create an overall financial self-efficacy scale $(\alpha=.70)$. Table 1 presents the correlations between financial self-efficacy, self-esteem, and credit card risk.

\section{Results}

\section{$\underline{\text { Insert Table } 1 \text { about here }}$}

Manipulation check. Participants in the control-present condition were more likely than participants in the control-absent condition to indicate that the article emphasized taking control $\left(\mathrm{M}_{\text {present }}=6.23, \mathrm{M}_{\mathrm{absent}}=3.72, t(218)=-11.00, p<.001\right)$. 
Credit card risk. Participants in the control-present condition reported marginally less willingness to take risk than participants in the control-absent condition $\left(\mathrm{M}_{\text {present }}=3.04\right.$, $\left.\mathrm{M}_{\mathrm{absent}}=3.32, t(218)=1.67, p<.1\right)$.

Moderated mediation analysis. Following Hayes (2013), we conducted a moderated mediation analysis using Model 7 with control priming and self-esteem as the independent variables, financial self-efficacy as the mediator, credit card risk as the dependent variable, and credit card debt and monthly personal income as covariates. The variables were mean-centered in order to facilitate the interpretation of the results. As seen in Table 2, the results indicated that self-esteem had a significant conditional effect $(\mathrm{B}=1.5, \mathrm{t}(212)=2.40, p<.05)$, and that there was a significant interaction between control priming and self-esteem that predicted financial selfefficacy $(\mathrm{t}(212)=2.64, p<.01)$. Financial self-efficacy had a negative effect on willingness to take credit card risk $(\mathrm{B}=-.41, \mathrm{t}(212)=-6.40, p<.001)$, which suggests that lower self-efficacy contributed to a higher willingness to take credit card risk. In addition, the moderated mediation index was significant (CIs -.2596 to -.0496). Most importantly, control priming had a significant negative conditional indirect effect on willingness to take credit card risk $(\mathrm{B}=-.19)$ for participants whose self-esteem score was one standard deviation above the mean (CI: -.4358 to .0206). This means that control priming increased the self-efficacy of participants with high selfesteem, thus reducing their willingness to take credit risk. Surprisingly, there was a significant positive indirect effect for participants whose self-esteem score was one standard deviation below mean (CI: .0060 to .3742). That is, control priming decreased the self-efficacy of participants with self-esteem scores one standard deviation below the mean, thus increasing their willingness to take credit card risk. For those with self-esteem scores around the mean, there was no significant conditional indirect effect. 


\title{
Discussion
}

\author{
Insert Table 2 about here
}

The results of Study 2 replicated the findings of the Study 1A and B using a different measure of irresponsible financial behavior and a different method of priming control. Control priming was most beneficial for participants with high self-esteem. These participants experienced higher self-efficacy after control priming, which reduced their willingness to engage in irresponsible financial behaviors. Interestingly, control priming made participants with low self-esteem more likely to engage in irresponsible financial behavior. One explanation for this result may be that low self-esteem individuals tend to be less accepting of optimistic messaging (Baumeister, et al. 2003). Thus, they may have found the control-priming message about taking control of their lives to be threatening.

\section{General Discussion}

This research introduces a promising method that could be helpful in addressing a large and growing social problem. The findings of the three studies presented in this paper suggest that using thoughts of control to prime consumers could be an effective way of reducing financially irresponsible behaviors assessed in the current research via credit card spending (Study 1A), gambling (Study 1B), and credit card risk (Study 2). Furthermore, the results demonstrate that the effects of control priming last for at least one month, as the follow-up questionnaires revealed that control-primed participants had reduced their credit card spending by an average of $\$ 130$ in the month since participating in the study. The robustness of the effects across various measures of irresponsible financial behavior is encouraging, as is the demonstration of effects across various samples of consumers (students in Study 1A and the general population in Studies 1B and 2). 
The investigation of the mediating role of self-efficacy documented in this article represents a theoretical contribution to the literature, as our findings indicate that control priming increases financial self-efficacy and thus decreases irresponsible financial behavior. A second theoretical contribution is the identification of a boundary condition of the effects of control priming: self-esteem. Participants with high levels of self-esteem benefitted the most from priming. Following control priming, these individuals showed higher self-efficacy related to debt management and reported less willingness to take irresponsible financial behavior. Importantly, priming had the opposite effect for individuals with low self-esteem; that is, participants with low self-esteem were more willing to engage in irresponsible financial behavior following control priming.

There has been little research investigating interventions that can help motivate consumers to reduce their debt. Although the behavioral change literature has explored interventions in several domains, including weight control (Harderman, Griffin, Johnston, Kinmonth, and Wareham 2000), exercise promotion (Conn, Valentine, and Cooper 2002), and smoking cessation (Armitage and Arden 2008), our research adds to the literature that addresses behavioral change with regards to irresponsible financial behaviors.

It is worth noting that the manipulations employed in this research relied on the control priming aspect of attributional retraining, which is not as strong as other methods more commonly used in the literature. Traditionally, researchers have employed several phases, including a reflection phase wherein participants reflect on what it means to take control (Hall, Hladkyj, Perry, and Ruthing 2004; Haynes Stewart et al. 2011). Nonetheless, our research shows that a simple manipulation, such as reading an article or watching a video that emphasizes taking control, can be effective. Because the short and efficient priming manipulation used in this study 
still showed significant effects one month after the intervention, we believe that even brief reminders of controllability (including the use of brochures, pop up ads, etc.) could help consumers continue to avoid irresponsible financial behaviors. This would be an interesting subject to pursue in future research.

In addition to long-term benefits, there are a few other promising avenues for future research. In our experiments, we did not measure participants' self-control with regards to spending, yet this is a measure that has been proven to be an effective predictor of financial behavior (Bearden and Haws 2012). Indeed, past research has shown that people with low spending self-control can benefit most from strategies aimed at encouraging responsible financial behavior (Haws et al. 2012). It would be interesting to examine whether control priming is more beneficial for consumers with low spending self-control than it is for those with high spending self-control. Second, future research may incorporate other factors that affect perceptions of financial control, such as economic mobility (Dividai and Gilovich 2015). Consumers who perceive the possibility of economic mobility will behave in a more financially responsible manner with the goal of achieving future economic success. This is particularly true of materialists. Perhaps control priming will enhance the belief that economic mobility is possible, thus reducing irresponsible financial behavior. Third, control priming may prove to be effective in other consumer contexts where loss of control is experienced, for example, compulsive eating, physical inactivity, and compulsive shopping (Billieux, Rochat, Rebetez, and Van der Linden 2008; Latner, Mond, Kelly, Haynes, and Hay 2014). Moreover, control priming may be an effective method of combatting the growing problem of compulsive Internet use (SteinerAdair 2015). Given that internet addiction is associated with a sense of loss of control (Kuss, 
Griffiths, Karila, and Billieux 2014), interventions like the ones in the above-described studies may prove to be highly beneficial.

In summary, this research shows that control priming is a successful method for reducing irresponsible financial behavior because it increases financial self-efficacy. In particular, control priming is especially beneficial for individuals with higher levels of self-esteem. We believe that control priming constitutes a successful intervention that can be used in conjunction with other commonly used behavioral change interventions, such as goal setting, self-monitoring, and social encouragement (Harderman et al., 2000; Abraham and Michie, 2008), to motivate individuals to adopt positive behaviors. 


\section{References}

Abraham C, Michie S (2008) A taxonomy of behavior change techniques used in interventions. Health Psychology 27(3): 379-387. doi:10.1037/0278-6133.27.3.379

Armitage CJ, Arden MA (2008) How useful are the stages of change for targeting interventions? Randomized test of a brief intervention to reduce smoking. Health Psychology 27(6): 789798. doi:10.1037/0278-6133.27.6.789

Bandura A (1977) Self-efficacy: Toward a unifying theory of behavioral change. Psychological Review 84(2): 191-215. doi:10.1037/0033-295X.84.2.191

Bandura A (1986) Social foundations of thought and action: A social cognitive theory. PrenticeHall, Inc, Englewood Cliffs NJ

Baumeister, R F (2002) Yielding to temptation: Self-control failure, impulsive purchasing, and consumer behavior. Journal of Consumer Research 28(4): 670-676. doi:10.1086/338209

Baumeister RF, Campbell JD, Krueger JI, Vohs KD (2003) Does high self-esteem cause better performance, interpersonal success, happiness, or healthier lifestyles? Psychological Science in the Public Interest 4(1):1-44.

Bearden WO, Haws KL (2012) How low spending control harms consumers. Journal of the Academy of Marketing Science 40(1): 181-193. doi:10.1007/s11747-011-0282-1

Billieux J, Rochat L, Rebetez ML, van der Linden M (2008) Are all facets of impulsivity related to self-reported compulsive buying behavior? Personality and Individual Differences 44(6):1432-1442. doi:10.1016/j.paid.2007.12.011

Conn VS, Valentine JC, Cooper HM (2002) Interventions to increase physical activity among aging adults: A meta-analysis. Annals of Behavioral Medicine 24(3):190-200. doi:10.1207/S15324796ABM2403_04 
Davidai S, Gilovich T (2015) Building a more mobile America—One income quintile at a time. Perspectives on Psychological Science, 10(1): 60-71. doi: $10.1177 / 1745691614562005$

Federal Reserve Bank of New York (2017) Quarterly report on household debt and credit. https://www.newyorkfed.org/microeconomics/hhdc.html. Accessed June, 6, 2017

Financial Consumer Agency of Canada (2012) Choosing the right credit card for you. http://www.fcac-acfc.gc.ca/Eng/resources/publications/creditCards/Pages/ChoosingChoisirl-2.aspx. Accessed February, 27, 2015

Fitch G (1970) Effects of self-esteem, perceived performance, and choice on causal attributions. Journal of Personality and Social Psychology 16(2): 311-315. doi:10.1037/h0029847

Gathergood J (2012) Self-control, financial literacy and consumer over-indebtedness. Journal of Economic Psychology 33(3): 590-602. doi:10.1016/j.joep.2011.11.006

Gist ME, Mitchell TR (1992) Self-efficacy: A theoretical analysis of its determinants and malleability. Academy of Management Review 17(2): 183-211.

Hall NC, Hladkyj S, Perry RP, Ruthing JC (2004) The role of attributional retraining and elaborative learning in college students' academic development. Journal of Social Psychology 144(6): 591-612.

Hall NC, Perry RP, Chipperfield JG, Clifton RA, Haynes TL (2006) Enhancing primary and secondary control in achievement settings through writing-based attributional retraining. Journal of Social and Clinical Psychology 25(4): 361-391. 
Hardeman W, Griffin S, Johnston M, Kinmonth AL, Wareham NJ (2000) Interventions to prevent weight gain: A systematic review of psychological models and behaviour change methods. International Journal of Obesity 24(2): 131-143.

Haws KL, Bearden WO, Nenkov GY (2012) Consumer spending self-control effectiveness and outcome elaboration prompts. Journal of the Academy of Marketing Science, 40(5): 695710. DOI 10.1007/s11747-011-0249-2

Hayes AF (2013) Introduction to mediation, moderation, and conditional process analysis: A regression-based approach. Guilford Press, New York

Hayhoe CR, Leach L, Turner PR (1999) Discriminating the number of credit cards held by college students using credit and money attitudes. Journal of Economic Psychology 20: 643-656. doi:0.1016/S0167-4870(99)00028-8

Haynes Stewart TL, Clifton RA, Daniels LM, Perry RP, Chipperfield JG, Ruthig JC (2011) Attributional retraining: Reducing the likelihood of failure. Social Psychology Education 14(1): 75-92. doi:10.1007/s11218-010-9130-2

Hsee CK, Weber EU (1999) Cross-national differences in risk preferences and lay predictions for the differences. Journal of Behavioral Decision Making 12: 165-179.

Kamleitner B, Erki B (2013) Payment method and perceptions of ownership. Marketing Letters 24(1): 57-69. doi:10.1007/s11002-012-9203-4

Kettle K, Trudel R, Blanchard S, Häubl G (2016) Repayment concentration and consumer motivation to get out of debt. Journal of Consumer Research 43(3): 460-477. doi:10.1093/jcr/ucw037 
Kuss DJ, Griffiths M, Karila L, Billieux J (2014) Internet addiction: A systematic review of epidemiological research for the last decade. Current Pharmaceutical Design 20(25): 40264052.

Latner JD, Mond JM, Kelly MC, Haynes SN, Hay PJ (2014) The loss of control over eating scale: Development and psychometric evaluation. International Journal of Eating Disorders 47(6): 647-659. doi:10.1002/eat.22296

Leventhal H, Perloe SI (1962). A relationship between self-esteem and persuasibility. The Journal of Abnormal and Social Psychology 64(5): 385-388. doi:10.1037/h0046368

Lea S, Webley P, Levine RM (1993) The economic psychology of consumer debt. Journal of Economic Psychology 13: 111-134. doi:10.1016/0167-4870(93)90041-I

Levav J, Argo JL (2010) Physical contact and financial risk-taking. Psychological Science 21(6): 804-810. doi:I O.I 177/0956797610369493

Lown JM (2011) Development and validation of a financial self-efficacy scale. Journal of Financial Counseling and Planning 22(2): 54-63.

Luzzo DA, Funk DP, Strang J (1996) Attributional retraining increases career decision-making self-efficacy. Career Development Quarterly 44(4): 378-386. doi:10.1002/j.21610045.1996.tb00453.x

Luzzo DA, James T, Luna M (1996) Effects of attributional retraining on the career beliefs and career exploration behaviour of college students. Journal of Counselling Psychology 43: 415-422. doi:10.1037/0022-0167.43.4.415

McFarlin DB, Blascovich J (1981) Effects of self-esteem and performance feedback on future affective preferences and cognitive expectations. Journal of Personality and Social Psychology 40(3): 521-531. doi:10.1037/0022-3514.40.3.521 
Muraven M (2010) Building self-control strength: Practicing self-control leads to improved selfcontrol performance. Journal of Experimental Social Psychology, 46(2): 465-468. doi: 10.1016/j.jesp.2009.12.011

Oaten M, Cheng K (2007) Improvements in self-control from financial monitoring. Journal of Economic Psychology 28(4):487-501. doi: 10.1016/j.joep.2006.11.003

Perry RP, Penner KS (1990) Enhancing academic achievement in college students through attributional retraining and instruction. Journal of Educational Psychology 82: 262-271. doi:10.1037/0022-0663.82.2.262

Perry VG, Morris MD (2005) Who is in control? The role of self-perception, knowledge, and income in explaining consumer financial behavior. Journal of Consumer Affairs 39(2): 299-313. doi:10.1111/j.1745-6606.2005.00016.x

Plunkett HR, Buehner MJ (2007) The relation of general and specific locus of control to intertemporal monetary choice. Personality and Individual Differences 42(7): 1233-1242. doi:10.1016/j.paid.2006.10.002

Rosenberg M (1965) Society and the adolescent self-image. Princeton University Press, Princeton

Ruthig JC, Perry RP, Hall NC, Hladkyj S (2004) Optimism and attributional retraining longitudinal effects on academic achievement, test anxiety and voluntary course withdrawal in college students. Journal of Applied Social Psychology 34: 709-730. doi:10.1111/j.1559-1816.2004.tb02566.x

Steiner-Adair C (2015) Are you addicted to the Internet? CNN. http://www.cnn.com/2015/07/17/opinions/steiner-adair-internet-addiction/index.html. Accessed June 12, 2017 
Tangney JP, Baumeister RF, Boone AL (2004) High self-control predicts good adjustment, less pathology, better grades, and interpersonal success. Journal of Personality 72(2): 271-324. doi: 10.1111/j.0022-3506.2004.00263.x

Taylor KM, Popma J (1990) An examination of the relationships among career decision-making self-efficacy, career salience, locus of control, and vocational indecision. Journal of Vocational Behavior 37(1): 17-31. doi:10.1016/0001-8791(90)90004-L

Weiner B (1986) An attribution theory of motivation and emotion. Springer-Verlag, New York

Weiner B, Litman-Adizes T (1980) An attributional expectancy-value analysis of learned helplessness and depression. In: Garber J, Seligman MEP (eds) Human helplessness: theory and applications. Academic Press, New York, pp 35-57

Wilcox K, Block LG, Eisenstein EM (2011) Leave home without it? The effects of credit card debt and available credit on spending. Journal of Marketing Research 48(SPL): S78-S90. doi:10.1509/jmkr.48.SPL.S78

Xiao JJ, Tang C, Serido J, Shim S (2011) Antecedents and consequences of risky credit behavior among college students: Application and extension of the theory of planned behavior. Journal of Public Policy \& Marketing 30 (2): 239-245. doi:10.1509/jppm.30.2.239 Yamanchi KT, Templer DJ (1982) The development of a money attitude scale. Journal of Personality Assessment 46: 523-528.

Yoon S, Kim HC (2016) Keeping the American dream alive: The interactive effect of perceived economic mobility and materialism on impulsive spending. Journal of Marketing Research 53(5): 759-772. doi:10.1509/jmr.15.0053 
TABLE 1

Study 2: Correlations between Self-esteem, Self-efficacy, and Credit Card Risk

\begin{tabular}{|l|r|r|r|}
\hline & \multicolumn{2}{|c|}{ Self-Esteem } & \multicolumn{2}{|c|}{$\begin{array}{c}\text { Financial Self- } \\
\text { Efficacy }\end{array}$} & Credit Card Risk \\
\hline Self-Esteem & 1 & $.185^{* *}$ & \multicolumn{1}{|c|}{$7^{*}$} \\
\hline Financial Self-Efficacy & $.185^{* *}$ & 1 & $-.398^{* *}$ \\
\hline Credit Card Risk & $-.137^{*}$ & $-.398^{* *}$ & 1 \\
\hline
\end{tabular}

**. Correlation is significant at the 0.01 level (2-tailed).

*. Correlation is significant at the 0.05 level (2-tailed). 
TABLE 2

Study 2: Results of Moderated Mediation Analysis Predicting Credit Card Risk Mediator Model:

Control priming

Outcome: Self-efficacy (coeff, $t$ )

Self-esteem

$.040(.25)$

Control Priming x Self-esteem

$.150(2.40)^{*}$

Credit card debt owed

$.329(2.64) * *$

Personal income

Adjusted $R^{2}$

$-.000(-3.87)^{* * * *}$

d.f.

$.000(-.93)$

$F$

.1312

$(5,212)$

$6.40 * * *$

\section{Model:}

Outcome: Credit card risk

Self-efficacy

Control priming $-.412(-6.40) * * *$

Credit card debt owed

$-.26(-.170)$

Personal income

$.00(-1.21)$

Adjusted $R^{2}$

$.00(2.05)^{*}$

d.f.

.1920

$(4,213)$

F

$12.65 * * *$

\begin{tabular}{llcc}
\hline & & \multicolumn{2}{c}{$\mathrm{BCa}^{\mathrm{a}}$ 95\% CI } \\
\cline { 2 - 4 } & Effect & Lower & Upper \\
\hline $\begin{array}{l}\text { Direct effect of control } \\
\text { priming on credit card risk }\end{array}$ & -.2618 & -.5656 & .0420 \\
\hline
\end{tabular}

Conditional indirect effect of control priming on credit card risk at values of self-sufficiency

\begin{tabular}{lcrc}
\hline & & \multicolumn{2}{c}{$\mathrm{BCa}^{\mathrm{a}}$ 95\% CI } \\
\cline { 3 - 4 } Self-esteem & Effect & Lower & Upper \\
\hline Low & .1580 & .0060 & .3742 \\
Average & -.0166 & -.1500 & .1171 \\
High & -.1912 & -.4358 & -.0206 \\
\hline
\end{tabular}

Index of Moderated Mediation

\begin{tabular}{llr} 
& \multicolumn{2}{c}{$\mathrm{BCa}^{\mathrm{a}} 95 \% \mathrm{CI}$} \\
\cline { 2 - 3 } Effect & Lower & Upper \\
-.1358 & -.2596 & -.0496
\end{tabular}

${ }^{*} p<.05 .{ }^{* *} p<.01{ }^{* * *} p<.001$. 


\section{FIGURE 1}

Study Two: Proposed Model

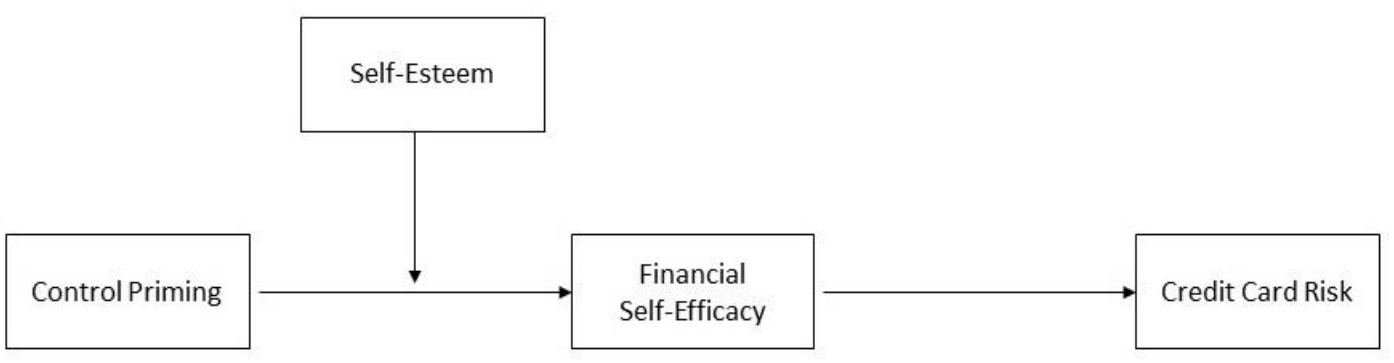




\section{Appendix A \\ Scenario Used in Studies $1 \mathrm{~A} \& 1 B$ \\ Condition: Control Priming Present My Path into Debt}

You have a job and you're earning a salary. It's time to start saving and setting some money aside in order to enjoy your upcoming vacation. Unfortunately, no matter how hard you try, you just can't save enough cash to open even a simple bank account.

Here is my story, and I am sure it is one that is familiar to many of you. As I entered university, I received an application for a credit card. And I thought to myself, I should fill in this application and I can put all my expenses on my credit card, gain some points and pay off the balance in full each month. I won't use it for anything that is not a necessity. So, I filled out the application for the card and was on my way to becoming financially independent. I have heard over and over again how important it is to establish a credit rating, and that is was I thought I was doing.

Before I knew it, I was in over my head. It was just so easy and I did not even think about. Until the bill came and the amount that I owed was more than I thought it would be. So, I thought to myself: well, this month I will pay half of the amount that is owed. I will be much more careful next month and I will be able to catch up. And then next month would come and I would be in the exact position that I was the month before, with a balance that I could not afford to pay off in full. After a few months, I started to realize the real cost of what I was doing as I watched the total that I owed increase each month with the interest that was accumulating.

The problem is that I was stuck neck-deep in debt and every penny that came into my pocket came right out again to pay for the interest on my debt. Not only were my debt levels not dropping, they were rising. I was contemplating on borrowing more money just to pay the interest charges on my current debt. I was not just using the card for necessities, but for more things than I realized: dinner out with friends, a night at the movies, etc.

So, I sat down one evening with my calculator and pretty much took control over my financial life. I realized that I needed to take control, and that I could be in control. I needed to always be vigilant and to remind myself that nobody but me caused my debt, and that nobody but me was going to get me out of the mess I was in. I took a second job that helped pay my debt. Now, I have been able to successfully pay off all my credit card debt. I know that I am in charge of what I am doing, and am in control of my spending and credit. I want to stay in control of my finances, and plan to keep the tools that I use now to manage my money with me as I start down a new path when student life is over. 


\section{Condition: Control Priming Absent My Path into Debt}

You have a job and you're earning a salary. It's time to start saving and setting some money aside in order to enjoy your upcoming vacation. Unfortunately, no matter how hard you try, you just can't save enough cash to open even a simple bank account.

Here is my story, and I am sure it is one that is familiar to many of you. As I entered university, I received an application for a credit card. And I thought to myself, I should fill in this application and I can put all my expenses on my credit card, gain some points and pay off the balance in full each month. I won't use it for anything that is not a necessity. So, I filled out the application for the card and was on my way to becoming financially independent. I have heard over and over again how important it is to establish a credit rating, and that is was I thought I was doing.

Before I knew it, I was in over my head. It was just so easy and I did not even think about. Until the bill came and the amount that I owed was more than I thought it would be. So, I thought to myself: well this month I will pay half of the amount that is owed. I will be much more careful next month and I will be able to catch up. And then next month would come and I would be in the exact position that I was the month before, with a balance that I could not afford to pay off in full. After a few months, I started to realize the real cost of what I was doing as I watched the total that I owed increase each month with the interest that was accumulating.

The problem is that I was stuck neck-deep in debt and every penny that came into my pocket came right out again to pay for the interest on my debt. Not only were my debt levels not dropping, they were rising. I was contemplating borrowing more money just to pay the interest charges on my current debt. I was not just using the card for necessities, but for more things than I realized: dinner out with friends, a night at the movies, etc.

I took a second job that helped pay my debt. I have been able to successfully pay off all my credit card debt. 


\section{Appendix B}

\section{Study 1B: Gambling Measures}

Suppose that you bought a lottery ticket a week ago. You are now informed that you have won and have been given two options of how to receive the money. What option would you choose in each scenario?

\section{Scenario \#1}

Option A: Receive $\$ 400$ for sure

Option B: Flip a coin; receive $\$ 2000$ if Heads or $\$ 0$ if Tails

\section{Scenario \#2}

Option A: Receive $\$ 600$ for sure

Option B: Flip a coin; receive $\$ 2000$ if Heads or $\$ 0$ if Tails

\section{Scenario \#3}

Option A: Receive $\$ 800$ for sure

Option B: Flip a coin; receive $\$ 2000$ if Heads or $\$ 0$ if Tails

\section{Scenario \#4}

Option A: Receive $\$ 1000$ for sure

Option B: Flip a coin; receive $\$ 2000$ if Heads or $\$ 0$ if Tails

\section{Scenario \#5}

Option A: Receive $\$ 1200$ for sure

Option B: Flip a coin; receive $\$ 2000$ if Heads or $\$ 0$ if Tails

\section{Scenario \#6}

Option A: Receive $\$ 1400$ for sure

Option B: Flip a coin; receive \$2000 if Heads or \$0 if Tails

\section{Scenario \#7}

Option A: Receive $\$ 1600$ for sure

Option B: Flip a coin; receive \$2000 if Heads or \$0 if Tails 


\section{Appendix C}

\section{Scenarios Used in Study 2}

\section{Condition: Control Absent}

I sat down one evening and read a book. I realized how much I loved reading. I like many genres, including fiction and romance. I started reading a new book once every two weeks. I feel that reading is the best way to spend an evening. I enrolled myself in a book club and pretty much enjoyed the experience. I have many other hobbies, including painting, cooking, and watching TV. I wish I had a lot of time to dedicate to each hobby.

\section{Condition: Control Present}

My problem was that my life was a mess. I sat down one evening and pretty much took control over my life. I realized that I needed to take control, and that I could be in control. I needed to always be vigilant and to remind myself that nobody but me caused my trouble, and that nobody but me was going to get me out of the mess I was in. I read a lot about how to take control of my life. I took a second job that helped better manage my life. Now, I have been able to successfully take control of my life; I know that I am in change of what I am doing and am in control of my life. I want to stay in control and plan to keep the tools that I use now to manage my life. 